\title{
La historia antigua de México en los textos escolares del siglo XIX
}

Patricia Escandón

Toda persona con un nivel medio de instrucción sabe historia o cree saberla porque, en el contexto de la vida cotidiana, la historia no pasa de ser una cierta acumulación organizada de hechos pasados más o menos significativos. En tránsito por la escuela elemental, se recibe un determinado corpus de información histórica nacional no susceptible de mayor cuestionamiento; así, se da por hecho que Cuauhtémoc fue héroe y mártir y Cortés un villano, que Hidalgo es el padre de la patria, que Santa Anna fue un traidor, que Juárez fue el paradigma de la integridad, que Madero fue un iluso, etcétera.

Estas "verdades históricas", que en bloque constituyen el acervo de erudición del común, forman parte de la versión oficial de la historia patria, del dogma sancionado por el Estado cuya transmisión y aprendizaje por parte de los educandos asegura la conservación de nuestras "tradiciones", nuestra "conciencia nacional" y, en suma, de nuestra "identidad".

Pero esto no siempre fue así; la génesis de esta historia oficial en México puede rastrearse allá, a mediados del siglo XIX, cuando las facciones conservadora y liberal se disputaban la hegemonía política del país. En esta lucha estaba en juego algo más que el simple acceso al poder; se trataba también de la imposición o triunfo definitivo de una visión retrospectiva de la vida nacional, y por tanto, de los derroteros futuros del país; al decir de Josefina Vázquez "se trataba de dos nacionalismos frente a frente: el conservador, con toda su nostalgia hispánica, su pesimismo, su antiyanquismo obsesivo, y el liberal, antiespañol, antiyanqui, antifrancés por algún tiempo, y con una medida de nostalgia indigenista, pesimista y defensiva". 1 Eran éstos, grupos antagonicos que interpretaban la realidad presente y los hechos pasados de una manera distinta y encontrada y que, en consecuencia, no habían de contemplar objetivamente a la historia de México como un proceso natural de desarrollo social, sino como una palestra donde se medían perennemente las fuerzas del bien y del mal.

En una guerra a muerte ya no se buscan razones ni se esgrimen argumentos, más bien se procuran paladines y estandartes que representen un elemento de cohesión o un factor de proselitismo para fortalecer al bando propio y derrotar al enemigo. A pesar de sus diferencias, tanto liberales como conservadores participaban de una inquietud común que los conducía a arrogarse el carácter de depositarios únicos de la verdad y la justicia, según sus miras particulares: la obligada búsqueda de la identidad nacional y la necesidad perentoria de transmitir ese conocimiento a las nuevas generaciones. El medio más efectivo y seguro para garantizar la formación de la niñez y la juventud en determinados principios es, indudablemente, la escuela; ambos partidos eran conscientes 
de ello, sin embargo, tocó en suerte a los liberales - al fin de la guerra de los Tres Años - poner en práctica sus teorías educativas.

En 1859 se dispuso que la enseñanza de la historia patria fuera obligatoria en la escuela elemental; en 1891 la lectura de las leyes fundamentales del país en las escuelas primarias adquirió el mismo carácter. Con todo, no parece que se hubiera avanzado mucho en ese terreno, pues unos cuantos años después de que estas disposiciones entraran en vigor, Justo Sierra señalaba que "el estudio de la historia del país... ningún pueblo de la tierra lo ve con más culpable abandono que nosotros". 2 Roa Bárcena secundaba tal opinión en estos términos: "Estamos presenciando la no poco perjudicial anomalía de que mientras los jóvenes suelen salir versados en la historia antigua y moderna de otros países, carecen hasta de las más ligeras nociones de la propia..." 3 Otro gran pensador, José María Vigil, se lamentaba hacia 1878 del descuido y negligencia en que se tenían los estudios historicos respecto a la educación científica y literaria "y aboga por una dedicación intensiva hacia ellos como el medio más adecuado para profundizar sobre la realidad mexicana; es decir, se plantea el estudio de la historia nacional como instancia de salvación de lo esencial y propio". 4

Para subsanar las deficiencias educativas de las que hablaban estos autores y ante la ausencia de un programa o plan de estudios, toda vez que la historia nacional se ganó un sitio en la escuela elemental, se hizo necesario contar con libros de texto que constituyeran una guía para el maestro y un vínculo de aprendizaje para el alumno de aquellos aspectos que debían tratarse en la lección o cátedra. Esta labor, sin embargo, ofrecía dificultades: "Uno de los principales obstáculos en la elaboración de libros de texto de historia era, sin duda, la falta de buenas síntesis de historia de México. [otro], lo constituía el método catequístico, tan difícil de manejar y que parecía dar por resultado el convencer a los niños de la inutilidad de la historia." 5

Antes de entrar de lleno al análisis de este último punto, parece oportuno señalar que este pequeño artículo no aspira a estudiar a fondo los problemas que presentó el desarrollo de los cursos de historia patria o de los programas posteriormente implantados en las instituciones de educación elemental y superior durante la segunda mitad del siglo XIX, si bien no dejaremos de referirnos más adelante a ello; de momento, sólo interesa hacer reflexiones en torno a algunos de los textos que se emplearon para la enseñanza de la historia. Asentado esto, se puede decir que, efectivamente, las obras históricas de que se disponía por entonces no eran lo más a propósito para introducir a los párvulos al conocimiento de la historia de México. Amén de las historias generales y crónicas del periodo colonial, estaban los trabajos de historiadores formales y concienzudos como Alamán, Bustamante, Zerecero y otros; también se contaban los escritos y publicaciones de fuentes que hicieran Orozco y Berra, Ramírez y García Icazbalceta, todo ello material de sumo valor

2 Ibid, p. 71.

3 José María Roa Bárcena, Catecismo elemental de la historia de México, desde su fundación hasta mediados del siglo XIX. Formado con vista de las mejores obras y propio para servir de texto a la enseñanza de este ramo en nuestros establecimientos de instrucción pública, 3a. ed., corregida, México, Imprenta de F. Díaz de León y S. White, 1870, p. 4.

4 Juan A. Ortega y Medina, Polemicas y ensayos mexicanos en torno a la historia, notas e índice onomástico por Eugenia Meyer, México, UNAM, 1970, 476 p. (Serie documental, núm. 8), p. 261.

5 Vázquez, op. cit., p. 75, 77. 
pero que no reunía los requisitos que demandaba la enseñanza en las escuelas elementales, a saber:

1) Exponer en forma sencilla y breve los conceptos básicos.

2) Cubrir, de manera general, los acontecimientos importantes de la historia patria.

3) Aportar la orientación ideológica deseable para el Estado.

En cuanto a los catecismos de historia, bien que vilipendiados y muchos de ellos con razón, facilitaban al educando la asimilación de los conocimientos, que aunque en la mayoría de los casos no quedaban sino en eso: textos cuya información debía ser memorizada y no comprendida cabalmente. Además, muchas de estas obritas:

exageraban el uso del método, hasta dejar reducido el relato a conceptos sin sentido. Como ejemplo, tendríamos el aparecido bajo las iniciales E. R.: Lecciones sencillas de Historia de México, Política y Aritmética Azteca:

- ¿Qué sucedió con el México antiguo?

-Acabó

- ¿Y en su lugar?

-Fue mandado a construir el México moderno o conquistado, a cuya obra ayudaron los mismos aztecas ${ }^{6}$

A pesar de la existencia de casos como el arriba señalado, cabe decir que los catecismos de historia fueron - en la variante de libros de texto- uno de los géneros más socorridos durante el siglo XIX, aunque de hecho pocos se hicieron acreedores al calificativo de aceptables.

Para efectos de análisis, se tomaron 10 textos de historia que van de los años 1870 a 1894, debidos a los siguientes autores: Manuel Payno (1870), José María Roa Bárcena (1870), Longinos Banda (1878), Tirso Córdoba (1881), Guillermo Prieto (1886), Antonio García Cubas (1890), Ramón Lainé (1890), Julio Zárate (1891), Aurelio María Oviedo y Romero (1894) y Justo Sierra (1894).

De estas 10 obras seleccionadas, cinco son catecismos y cinco - las de Payno, Prieto, García Cubas, Zárate y Sierra - son narraciones, compendios o lecciones, lo que a modo de muestra indica lo difundido del género catequístico frente a las otras formas. Todavía a fines del XIX Guillermo Prieto se quejaba de lo escaso y deficiente del material de lectura que se empleaba para la instrucción primaria. Vale la pena hacer la cita textual de su evaluación:

Los libros que han circulado hasta hoy en las escuelas, o son registros, como el de Rivera Cambas, o abreviaciones como el compendio de Buenrostro, o ecos del partido conservador, como Roa Bárcena y Córdova, o compendios como el de Payno, no narraciones correctas y exactas, pero sin comentario alguno como el de Zárate.

Pero gobierno y ayuntamiento, por ignorancia suprema o por indiferencia punible, se han atenido a la baratura, sin otra mira ni criterio.

Lo único que conocemos como más aceptable son: el compendio de Justo Sierra, que no es posible plantear por el costo de éste y por la ignorancia de los maestros; el compendio de García Cubas como recordación y no como enseñanza por la acumulación de fechas y nombres; las lecciones de Manterola 
...el compendio de Pérez Verdía... y si se me permite citar, el de Guillermo Prieto... ${ }^{7}$

Retomando un poco la idea que se manejo al principio, esto es, la del enfrentamiento entre conservadores y liberales, puede hablarse también de la existencia de dos corrientes o interpretaciones de la historia de México que eran igualmente contradictorias y polémicas. Una de ellas, la llamada "escuela española", ferviente admiradora del pueblo conquistador y la otra, la "escuela mexicana", reivindicadora del pasado indígena, que abjuraba de la raza que "por medio del hierro y el fuego" hizo entrar al Nuevo Mundo al "rezago de la civilización cristiana". Ambas tendencias están presentes en estos libros de texto, los unos prodigando alabanzas a Cortés y a la cultura española de la que, según proponen los autores, los mexicanos somos legítimos herederos, y los otros, ensalzando a Cuauhtémoc y a Hidalgo. De la muestra consignada sólo dos son los textos de tendencia conservadora: los de Roa Bárcena y Tirso Córdoba, que tambien, casualmente, tienen fechas relativamente tempranas de publicación. El resto de los trabajos analizados se afilia a la corriente liberal.

La historia antigua de México en estas obras viene a ser más o menos la piedra de toque, indicadora del valor, importancia y relación que estos autores conceden al periodo prehispánico respecto a la realidad nacional de su momento.

En cuatro de los trabajos estudiados hay una parte inicial o introducción que divide las etapas de la historia de México; hay que decir, sin embargo, que a este respecto no aparece ninguna unidad de criterio. Por ejemplo, para Banda (1878), la historia prehispánica se inserta en la división que él denomina "historia antigua", periodo que a su vez se desglosa en: 1) tiempos obscuros o inciertos, 2) tiempos heroicos o fabulosos y 3) tiempos históricos.

Ramón Lainé y Aurelio Oviedo y Romero distinguen en cambio seis épocas en la historia de México, correspondiendo la primera de ellas, o "época aborigen", al periodo comprendido entre los tiempos más remotos de que se tiene noticia y el año de 1521 que fue el de la caída de Tenochtitlan.

García Cubas presenta una división en tres partes, la primera de las cuales es la "historia antigua", división integrada por las "historias" de cuatro "grupos" o "pueblos": 1) pueblos de remota antigüedad y de ignorada historia, 2) pueblos trashumantes, sin domicilio fijo, 3) pueblos más o menos civilizados y 4) pueblos que dejaron anales.

Estas anárquicas ordenaciones son manifestaciones clásicas del espíritu del siglo XIX, que al impulso del desarrollo de las ciencias naturales, generó una manía clasificatoria para todos los ámbitos del saber humano. Todo era, pues, susceptible de divisiones, subdivisiones y agrupaciones - más o menos convencionales o relativas - para efectos de análisis ulterior, en el mejor de los casos, y por lo común, para una simple esquematización. Para la cuestión que nos ocupa, en lo único que coinciden estas cuatro "muestras" es en designar a la etapa prehispánica como "historia antigua" y en atribuirle un carácter obscuro, remoto e incierto en sus orígenes. 
Para todos los autores que aquí analizamos, la historia -en su sentido más amplio - tiene un fin pragmático, moralizante, instructivo; respecto al estudio de la historia prehispanica en particular, bien que no se especifique, lo consideraban un medio seguro de formar a la niñez en los "valores nacionales", en la conciencia de un orgullo por los antepasados que sirviera para encauzar la vida futura del país. Veamos algunos ejemplos: Jose María Roa Bárcena decía que el conocimiento de la historia tenía como fin evitar que los jovenes “...entraran con tal ceguera en la vida política, cuyo norte más seguro, después de la justicia, es el antecedente del país en cuya administración se toma parte". 9 Para Longinos Banda, 10 la lectura de temas históricos y la reflexión posterior es un ejercicio que fortalece e ilustra el entendimiento, al tiempo que Guillermo Prieto dice que la historia "es la consignación de hechos pasados que nos aleccionan en el presente y futuro, para regirnos por las leyes de la sana moral, perfeccionando nuestro ser y haciéndonos aptos para concurrir a la grande obra del progreso de la humanidad". 11 Opinión que manifiesta compartir Justo Sierra cuando señala "Recurra siempre el maestro en sus explicaciones al sistema de comparar lo presente y lo pasado para inculcar la noción de adelantamiento y progreso y desenvolvimiento, base de la historia." 12 Adviértase que en las dos últimas obras citadas se percibe con toda claridad una cierta influencia de la corriente positivista en la educación.

Ahora bien, en un análisis estrictamente físico de los trabajos de los diez autores consultados, ocho conceden a sus apartados sobre historia prehispánica más o menos una cuarta parte de la extensión total de la obra; solamente Payno y Lainé destinan - en proporción - menos de un $10 \%$ de sus trabajos a dicho periodo. Otra nota común a esta obras es que los autores omitan la referencia a las fuentes manejadas. Para García Cubas, Lainé, Oviedo y Roa Bárcena la guía principal en cuanto a temas prehispánicos la constituyó la Historia antigua de México, debida al jesuita Francisco Javier Clavijero. Ya en esta época el empleo de dicha obra (publicada en el siglo XVIII) como fuente única, le parecía obsoleto a Prieto, quien apuntaba: "Clavijero es un historiador por su elevación de miras, por su patriotismo, por sus laboriosas indagaciones; pero en materia histórica antigua se han hecho posteriores y trascendentales indagaciones de primera importancia para un mexicano." 13 Ocasionalmente Payno y García Cubas mencionan el empleo de las obras de Orozco y Berra, aunque sin duda, el mejor documentado, único con aparato crítico, es el libro de Guillermo Prieto; sus fuentes incluyen a Ixtlixóchitl, Pimentel, Mendieta, Torquemada, Durán, Humboldt, Ramírez, Orozco y Berra, Chavero y otros.

Todas las obras aquí consideradas siguen, aproximadamente, una pauta común en el tratamiento de la historia indígena. Hacen - más o menos - una crónica de las principales culturas; en general, la línea

9 Roa Bárcena, op. cit., p. 4.

10 Longinos Banda, Catecismo de historia y cronologia mexicana, escrito para las escuelas primarias, Guadalajara, Tip. de Sinforoso Banda, 1878, p. 4.

11 Guillermo Prieto, Lecciones de historia patria, México, Tipografía de la Sría. de Fomento, 1886, p. V.

12 Justo Sierra, Primer año de historia patria.Elementos paralos alumnosdel tercer año primario obligatorio, ajustado al programa de la ley vigente, París-México, Librería de la Vda. de Ch. Bouret, 1894 , p. 7.

13 Ortega y Medina, op. cit., p. 294. 
dinástica tolteca-chichimeca-azteca. De cuando en cuando aparecen algunas referencias a otros complejos culturales, sobre todo al maya.

Las partes destinadas al estudio de los olmecas, zapotecas, xicalancas y otros grupos tempranos quedan insertas en el apartado de los pueblos cuya historia se pierde en un pasado ignoto y fabuloso; todavía no habían llegado los tiempos en los que la arqueología y los estudios antropológicos hicieran aportaciones al conocimiento histórico, así, la etapa propiamente "histórica" arranca con los toltecas - cultura cuyo origen fijan todos nuestros autores aproximadamente en el siglo VII de nuestra era. El desarrollo histórico de este grupo se continúa - por una especie de "primogenitura" - en el de los chichimecas y su legendario caudillo Xólotl, que una vez despojados de los restos de su barbarie llegan al valle de Anáhuac y se mezclan con los grupos sedentarios que lo ocupaban. Así se va transmitiendo este "linaje real", hasta llegar a los mexicas o aztecas, cuya cultura alcanzó una etapa de esplendor que llegó a su ocaso en 1521, con la caída de México-Tenochtitlan a manos de los españoles.

La extensión y profundidad con que se abordan los temas arriba señalados varían de autor a autor. Lo que sí es común a todos ellos es el tratamiento más detallado de la "dinastía" de los señores mexicas. A este respecto, deberá tenerse en cuenta que en todos estos libros de texto la orientación es netamente política. Por otra parte, esta forma de enlazar hábilmente la sucesión de gobernantes de una manera en apariencia ininterrumpida, o al menos con cortes bien definidos y suficientemente justificados, avala la transmisión de la legitimidad de un régimen a otro hasta desembocar en el presente en que los autores trabajan en sus obras.

Para Julio Zárate el tratamiento preferente que se daba a la cultura mexica se sostenía por su propio peso, dado que "Los mexicanos fueron los que constituyeron la principal y más poderosa de las naciones que habitaban antiguamente este país y los que lucharon por su independencia de una manera que será siempre memorable en la historia." 14 Sobre el mismo punto, Ramón Lainé señala que la importancia del estudio de dicha cultura radica en que “... fueron los [mexicanos] los que adquirieron mayor preponderancia, fundando la más poderosa de las naciones de Anáhuac".15 A esto, Manuel Payno agrega: "[fue] el imperio más poderoso y el que presentó a los conquistadores toda la resistencia de que fue capaz, y luchó por su independencia de una manera que será siempre memorable en la historia".16 En la transcripción de estas citas es más que evidente que Zárate se sirvió del texto de Payno en la elaboración de su propia obra.

Para estos historiadores liberales es preponderante el papel desempeñado por la lucha de resistencia que los mexicanos opusieron al conquistador. En el terreno de las ideas, las fuerzas "nacionales", representadas por la cultura mexica, hicieron frente al extranjero invasor, al hombre blanco que venía a hollar su territorio, a robar sus riquezas, a explotar a su pueblo; realidad dolorosamente experimentada en los años de la intervención francesa, aún muy recientes y muy vivos en la

14 Julio Zárate, Compendio de la historia general de México, París-México, Librería de la Vda. de Ch. Bouret, 1891, p. 38.

15 Ramón Lainé, Catecismo de historia general de Méjico; escrito para las escuelas elementales de la República Mejicana, 9a. ed., aumentada, México, Tip. La Providencia, 1890, p. 5.

16 Manuel Payno, Compendio de la historia de México; para el uso de los establecimientos de instrucción primaria, México, Imprenta de F. Díaz de León y Santiago White, 1870, p. 45 . 
memoria. No en balde Cuitláhuac y Cuauhtémoc son los héroes máximos de la gesta del pueblo mexica, pintados por estos autores con tonos grandilocuentes; calificados de "jóvenes valientes" y "dechados de patriotismo" y de otros adjetivos similares que Oviedo y Romero lleva a su punto culminante, al decir que el heroico Cuauhtémoc era "el más digno de nuestra admiración, de nuestro cariño, pues fue el mártir a quien sacrificó Cortés para afianzar su poder". 17 En páginas como éstas, escritas para la formación de los escolares, se encuentran sin duda los orígenes del "santoral" del Estado, que en años subsecuentes habría de consolidarse mediante la conmemoración de fechas importantes y la erección de monumentos y altares patrios.

El antepasado más remoto de los conservadores decimonónicos en su actitud servil ante el Segundo Imperio, lo representa Payno en la figura del traidor Ixtlixóchitl, de quien dice que "Fue el más grande enemigo de su propia Patria, de su propia raza y de sus hermanos mismos... [pues] firmo una alianza estrecha con el conquistador." 18 Ciertamente no es muy difícil desentrañar de los párrafos arriba citados el paralelismo que estos autores liberales hallaban entre la historia antigua y la historia a ellos casi coetánea.

Un punto en el que convergen las opiniones de historiadores liberales y conservadores, es el tocante a la religión indígena; en concreto a la del pueblo mexica. Con diferentes matices y epítetos, no hay uno que no la tilde de bárbara, sanguinaria, supersticiosa e idolátrica, en particular por lo que se refiere al asunto de los sacrificios humanos. A este respecto, tal vez sea Payno el más tolerante: "Fuera de los sacrificios bárbaros y odiosos que les prescribía su imperfecta religión, las costumbres de los aztecas en lo interior de la familia eran dulces y sencillas." ${ }^{19}$ También Roa Bárcena intenta atemperar un poco su juicio:

En su culto [de los mexicas], aunque supersticioso y bárbaro, como hemos dicho, no intervenía acción alguna contraria a la honestidad, de que siempre fueron celosos; que tenían alguna idea, aunque imperfecta, de un Ser Supremo, absoluto, independiente... y lo designaban con el nombre genérico de Teotl que significaba "Dios" y que los mexicanos y otros pueblos igualmente adelantados creían en la inmortalidad del alma... 20

García Cubas tiene aún otra observación que hacer en torno al aspecto moral de los indígenas, y ésta va dirigida a los educandos, con un fin evidentemente didáctico:

...vemos que la degradación de una sociedad produjo la destrucción de un imperio floreciente, que como el tolteca había adquirido un alto grado de esplendor bajo el justo gobierno de Mitl; que la tiranía y debilidad de un monarca como Moctezuma II fueron causa de la perdida de la nacionalidad azteca, a pesar de los sublimes esfuerzos de un Cuitlahuac y de un Cuauhtémoc... ${ }^{21}$

Aquí afloran de nuevo las virtudes republicanas retratadas en la historia prehispánica a pretexto de una reflexión sobre el fin de los grandes señoríos indígenas.

17 Aurelio María Oviedo y Romero, Nuevo catecismo de historia de México; arreglado para el uso de las escuelas elementales de la República Mexicana, México, Gallegos Hnos. Sucs., 1894, p. 12.

18 Payno, op. cit., p. 60.

19 Ibid, p. 79.

20 Roa Bárcena, op. cit., p. 18.

21 Antonio García Cubas, Compendio de la historia de México y de su civilización para uso de los establecimientos de instrucción primaria, México, Imp. del Sagrado Corazón de Jesús, 1890 , p. 7. 
Ningún estudio sobre la historia antigua de México quedaría completo sin una referencia a los descendientes de aquellas fabulosas culturas. Para nosotros, hoy día, también reviste interés el saber qué veían los historiadores que aquí estudiamos en los indígenas de su presente, de su entorno inmediato, y enterarnos de la explicación que podían dar a lo que el destino deparó a los herederos directos de Xólotl y de los señores mexicas. Sobre esto Payno señala escuetamente: "La raza indígena que hoy vemos, son los restos, degradados desde antes, de la clase que llamaban macehuales." ${ }^{22}$ Roa bárcena abunda un poco más en su explicación al indicar:

Las violencias de que fueron víctimas [los indios] durante la conquista y bajo diversos periodos de la época colonial, no obstante las leyes protectoras expedidas en favor suyo, y el apego a su propia raza y a sus antiguas costumbres, han hecho degenerar muchas de sus mejores cualidades, y los mantienen, generalmente hablando, retirados y atrasados en medio del movimiento intelectual y material de la sociedad de que forman parte. ${ }^{23}$

Independientemente de que existe un trasfondo de verdad en las afirmaciones de Payno y de Roa Bárcena, pues es un hecho que las cruentas guerras de conquista exterminaron casi totalmente a la casta gobernante, sacerdotal y guerrera - lo que en términos actuales correspondería a la "intelectualidad"- de los mexicas, no es menos cierto que el desprecio secular de la población "blanca" por esos seres vencidos que se aferraban a la pervivencia de sus hábitos y tradiciones ancestrales, rehusándose a incorporarse a la cultura occidental, influyó bastante en las apreciaciones "antropológicas" de los autores del XIX. Sobre esta postura, don Juan Ortega y Medina apunta “...una cosa es... [para estos pensadores] - como lo fue igualmente para Sigüenza y Góngora- el pasado cultural prehispánico, valioso desde cualquier punto de vista, y otra esos residuos de la tradición o cargas emocionales perturbadoras y pues, según su criterio negativas". ${ }^{24}$

Casi toda esta exposición se dedicó a un análisis somero de una pequeña muestra de textos de historia para la instrucción primaria. En ella, juzgamos más sobre el producto final, que sobre el fundamento teórico. en que se apoyaron sus autores, aunque se hicieran algunas anotaciones a este respecto. Y como no parece conveniente dejar trunco el relato en este brevísimo estudio del libro de texto de historia, hay que decir que entre los años de 1889 y 1890, se celebró en la ciudad de México el Primer Congreso Nacional de Instrucción Pública, presidido por don Justo Sierra, que declaró a la instrucción primaria laica, gratuita y obligatoria. Dicho Congreso tuvo efectos benéficos para la literatura didáctica, pues a raíz de él, el eminente pedagogo suizo-mexicano, Enrique Rébsamen dio a la luz su famosa Gúa metodológica para la enseñanza de la historia (1891), que fue el primer intento serio por profesionalizar y poner al día la didáctica de la historia, según los cánones vigentes por entonces en Europa. La obra de Rébsamen despertó gran polémica; entre sus críticos más importantes, o, mejor dicho, su crítico más importante fue Guillermo Prieto, quien en una serie de artículos, publicados en $E l$ Universal entre enero y febrero de 1891, dio a conocer su opinión sobre la Guía. 
Metodológicamente, Prieto no hizo objeción alguna al texto de Rébsamen; de hecho no había discrepancias entre ellos, salvo por un punto: Rébsamen abogaba por la imparcialidad y la tolerancia, aduciendo que el maestro no debía ponerse al servicio de ningún partido político, religioso o social, sino mantener ante todo el criterio de la verdad objetiva en la historia.

Este postulado fue el que provocó la ira de Guillermo Prieto, quien no puede concebir una historia "aséptica". La razón de Rébsamen

era una razón general, europeizante, y no una razón particular, circunstanciada y mexicana como la que Prieto liberalmente defendfa, incluso contra la libertad de ensefianza proclamada por la propia Constitución (1857)... para Prieto, en la escuela se nace a la patria, se respira la patria; y por patria entiende él, en primerísimo lugar, la fe en el progreso, lo que implica necesariamente hablarle al niño de política e incluso de religión. 25

Prieto no transige; el maestro está obligado, ante todo, a transmitir a las nuevas generaciones los principios de igualdad y libertad, en los que se asienta el liberalismo, lo que - en su opinión - implica también una condena a la conquista, al mundo colonial, al fanatismo de los conservadores, a las prebendas y privilegios eclesiásticos, etcétera.

Rébsamen respondió a los artículos del viejo liberal en un tono muy mesurado, alegando en su defensa el hecho de que su Guía no tenía por finalidad desviar al educando del amor patrio, sino precisamente lo contrario: incülcárselo a través del conocimiento de la verdad, la justicia, la belleza y las virtudes cívicas. Por otra parte apunta que la falta de profundidad que su obra pudiera mostrar respecto al análisis de la educación cívica, no es sino resultado de la votación de programas en el Primer Congreso Nacional de Instrucción, la que determinó que esta rama figurara como una asignatura especial, independiente de la Historia.

La continuación y el término de la polémica Prieto-Rébsamen ya no revisten mayor interés para el asunto que ahora nos ocupa; únicamente importa subrayar este caso como el que marca el inicio de la planeación y el debate sobre los estudios de historia en la escuela elemental. A este respecto, también puede decirse que a medida que se consolidaba un régimen político estable en México - y nos referimos, claro está al Porfiriato - los nombres que alguna vez representaron banderas de batalla, adalides de una causa, una facción o un principio (al fin y al cabo no más que hombres), perdieron sus perfiles humanos, se invistieron de un aura de divinidad y ascendieron a los altares de la patria, tomando cada uno el sitio que se le asignó de acuerdo al valor que se quisiera destacar o enaltecer. Del antiguo providencialismo de la historia colonial se pasó a un mesianismo manipulado en el que el régimen en turno representa ni más ni menos que al salvador del país, cuya versión de la historia nacional viene a ser una especie de árbol genealogico que termina en él mismo, prueba contundente de su legítima ascendencia de un linaje de héroes. En pocas palabras, una "relación de méritos y servicios" ya libre del apasionamiento sincero que preconizaran tanto liberales como conservadores.

Actualmente, la orientación en la enseñanza de la historia en la escuela primaria sigue siendo política, porque no ha variado mucho la vie- 
ja idea liberal de que el objetivo fundamental del conocimiento de la historia es fomentar el nacionalismo, por tanto, aún se cree en la necesidad de que el niño se identifique con su patria a través de la remembranza de los nombres, las fechas y las gestas heroicas.

El desarrollo de los textos para la enseñanza tuvo, y tiene aún, una trayectoria azarosa, accidentada, llena de saltos, estancamientos, caídas y retrocesos; los problemas que aquejaban a los antiguos educadores los siguen padeciendo nuestros maestros hoy día: la vastedad de la disciplina, la dificultad de diseñar un método adecuado para cada nivel, los interminables debates sobre la orientación ideológica, e inclusive, lo elevado de los costos de producción del libro.

Sin embargo, en la actualidad contamos con un problema adicional que hubiera dejado perplejos y boquiabiertos a los más combativos liberales: la penetración ideológica del imperialismo a través de los medios masivos de comunicación. Ni Cuauhtémoc con todo su abnegado heroísmo y sus valientes guerreros mexicas, Hidalgo y sus hordas feroces e indisciplinadas, Morelos, con sus grandes dotes de estratega, juntos, serían capaces de ganar una batalla al bombardeo publicitario de las trasnacionales norteamericanas. Uno se pregunta inevitablemente por el futuro de este país, de sus valores propios y de sus tradiciones, cuando descubre, por mero accidente, que apenas un $20 \%$ de una muestra de escolares entre los 7 y los 10 años de edad, es capaz de identificar al autor de la frase: "El respeto al derecho ajeno es la paz", y en cambio, un $90 \%$ de la misma muestra reconoce de inmediato el logotipo de una conocida marca de pastelitos y la imagen de un "superhéroe" de las tiras cómicas que produce el país vecino.

La nota anterior puede parecer graciosa, pero no podemos soslayar el hecho de que mientras no se le dé la debida importancia al rescate y conservación de los estudios históricos en México, y mientras no se atienda a la mejor manera de transmitir ese conocimiento a las generaciones jóvenes, podremos esperar que el futuro traiga consigo cualquier cosa, menos la preservación de la conciencia de una identidad nacional. 